\title{
Distinct physiological and metabolic reprogramming by highbush blueberry (Vaccinium corymbosum) cultivars revealed during long-term UV-B radiation
}

\author{
Ana Luengo Escobara,b, Miren Alberdi b,c, Patricio Acevedo d,e, Mariana Machado ${ }^{f}$, \\ Adriano Nunes-Nesi ${ }^{f}$, Claudio Inostroza-Blancheteaug and Marjorie Reyes-Díaz ${ }^{\mathrm{b}, c^{*}}$ \\ aPrograma de Doctorado en Ciencias de Recursos Naturales, Universidad de La Frontera, Temuco, 54-D, Chile \\ ${ }^{b}$ Center of Plant, Soil Interaction and Natural Resources Biotechnology, Scientific and Technological Bioresource Nucleus (BIOREN), Universidad de La \\ Frontera, Temuco, 54-D, Chile \\ 'Departamento de Ciencias Químicas y Recursos Naturales, Facultad de Ingeniería y Ciencias, Universidad de La Frontera, Temuco, 54-D, Chile \\ dDepartamento de Física, Facultad de Ingeniería y Ciencias, Universidad de La Frontera, Temuco, 54-D, Chile \\ eCenter for Optics and Photonics, Universidad de Concepción, Concepción, 4012, Chile \\ fMax Planck Partner Group at Departamento de Biologia Vegetal, Universidade Federal de Viçosa, Viçosa-Minas Gerais, 36570-900, Brazil \\ gNúcleo de Investigación en Producción Alimentaría, Facultad de Recursos Naturales, Escuela de Agronomía, Universidad Católica de Temuco, \\ Temuco, 56-D, Chile
}

\section{Correspondence}

*Corresponding author,

e-mail: marjorie.reyes@ufrontera.cl

Received 10 August 2016;

revised 4 November 2016

doi:10.1111/ppl.12536
Despite the Montreal protocol and the eventual recovery of the ozone layer over Antarctica, there are still concerns about increased levels of ultraviolet-B (UV-B) radiation in the Southern Hemisphere. UV-B induces physiological, biochemical and morphological stress responses in plants, which are species-specific and different even for closely related cultivars. In woody plant species, understanding of long-term mechanisms to cope with UV-B-induced stress is limited. Therefore, a greenhouse UV-B daily course simulation was performed for 21 days with two blueberry cultivars (Legacy and Bluegold) under UV-B $B_{B E}$ irradiance doses of $0,0.07$ and $0.19 \mathrm{~W} \mathrm{~m}^{-2}$. Morphological changes, photosynthetic performance, antioxidants, lipid peroxidation and metabolic features were evaluated. We found that both cultivars behaved differently under UV-B exposure, with Legacy being a UV-B-resistant cultivar. Interestingly, Legacy used a combined strategy: initially, in the first week of exposure its photoprotective compounds increased, coping with the intake of UV-B radiation (avoidance strategy), and then, increasing its antioxidant capacity. These strategies proved to be UV-B radiation dose dependent. The avoidance strategy is triggered early under high UV-B radiation in Legacy. Moreover, the rapid metabolic reprogramming capacity of this cultivar, in contrast to Bluegold, seems to be the most relevant contribution to its UV-B stress-coping strategy.

\footnotetext{
Abbreviations $-{ }^{1} \mathrm{O}_{2}$, singlet oxygen; ${ }^{3} \mathrm{Chl}$, triplet state of chlorophyll; AAPH, 2,2'-azobis (2-amidinopropane) dihydrochloride; AUC, area under decay curve; $A x$, antheraxanthin; DEPS, de-epoxidation state of the xanthophyll-cycle pigments; ETR, electron transport rate; FL, flavonoid; Fv/Fm, maximum quantum yield; LP, lipid peroxidation; Lt, lutein; MDA, malondialdehyde; NPQ, non-photochemical quenching; Nx, neoxanthin; NPK, Nitrogen, Phosphorus and Potassium; ORAC, oxygen radical antioxidant capacity; PAR, photosynthetically active radiation; Phe, phenolic acid; $\phi \mathrm{PSII}$, effective quantum yield of PSII; RGR, relative growth rate; ROS, radical oxygen species; RSC, ROS scavenging capacity; RuBisCO, ribulose-1,5-bisphosphate carboxylase/oxygenase; TA, total anthocyanin; TBARS, thiobarbituric acid reacting substances; TC, total carotenoid; TE, Trolox equivalent; TP, total phenol; UAC, UV-absorbing compound; Vx, violaxanthin; Zx, zeaxanthin; $\beta C a$, $\beta$-carotene.
} 


\section{Introduction}

Many regions in the Southern Hemisphere have been severely impacted by the decrease in the ozone layer, which has led to higher doses of UV-B radiation (between 280 and $320 \mathrm{~nm}$ ) reaching the earth's surface (Mckenzie et al. 2007). The interaction between ozone depletion and climate change can modify expectations regarding the future of UV-B scenarios, which maintain that this issue is a current concern (Ballare et al. 2011). Although UV-B radiation represents only a small fraction of the total solar spectrum, it has disproportionately large photobiological effects on plants because of its high energy, which has been extensively reviewed (Jansen et al. 1998, Kakani et al. 2003, Lidon et al. 2012, Kataria et al. 2014). A common negative effect of UV-B is the enhancement of reactive oxygen species (ROS) production generating oxidative stress, lipid peroxidation of biomembranes and organelles, including chloroplasts (He et al. 1994, Landry et al. 1995, Lidon and Ramalho, 2011). It has been demonstrated in Arabidopsis plants that short-term responses to UV-B exposure occur only at the level of primary metabolites (Kusano et al. 2011). This suggests that these responses allow the cell to promote later production of UV-B-absorbing secondary metabolites. In addition to metabolite reprogramming, UV-B irradiation damages the photosynthetic apparatus, negatively affecting its function through direct effects on both photosystem I and II (PSI and PSII) and consequently limiting the carbon assimilation (Pfündel 2003, Lidon and Ramalho 2011). Furthermore, it has been shown that UV-B radiation reduces the activity of ribulose-1,5-bisphosphate carboxylase/oxygenase (RuBisCO) and/or its protein amount in some plant species such as Oryza sativa (Takeuchi et al. 2002, Fedina et al. 2010) and Canavalia ensiformis (Choi and Roh 2003), affecting the $\mathrm{CO}_{2}$ assimilation. This radiation also impacts the stability of the chloroplast ultrastructure, affecting the light harvesting apparatus by inducing changes at the level of photosynthetic pigments (especially chlorophylls) and thus reducing photosynthesis (He et al. 1994, Hui et al. 2013, Kataria et al. 2014).

Carotenoids are known to have a role in UV-B photoprotection in Arabidopsis plants (Middleton and Teramura 1993). However, some evidence indicates a non-direct assignment of total carotenoids (TC) in UV-B protection as established in Avena sativa (Ruhland et al. 2007) and Fagopyrum esculentum (Gaberščik et al. 2002). By contrast, xanthophyll cycle pigments are involved in the dissipation of excess energy in plants (Baroli and Niyogi 2000). Under excessive light, the xanthophyll pigment zeaxanthin (Zx) rapidly undergoes de-epoxidation from violaxanthin $(V x)$, through the intermediate antheraxanthin (Ax). This reaction is reversed under dark conditions (Jahns and Holzwarth 2012). With respect to UV-B radiation, the participation of the xanthophyll cycle pool is still controversial. In this sense, Bolink et al. (2001) reported that while in Pisum sativum the levels of these pigments increased after UV-B exposure, in Phaseolus vulgaris they remained unchanged. Moreover, in $P$. sativum, it is suggested that violaxanthin de-epoxidase (VDE) is inhibited by UV-B, resulting in enhanced levels of $\mathrm{Vx}$.

Plants have evolved strategies to counteract the negative effects of UV-B radiation (Solovchenko and Merzlyak 2008). One of these is the accumulation of UV-B absorbing compounds [e.g. secondary metabolites such as phenolic acids (Phe), flavonoids (FL), hydroxycinnamic acid, etc.]. These compounds are accumulated mainly in epidermal cells, screening the amounts of UV-B radiation reaching the photosynthetic leaf tissues. They are considered an efficient avoidance UV-B-resistance mechanism, where the UV-B can cause damage (Li et al. 1993, Landry et al. 1995, Mazza et al. 2000, Kolb et al. 2001). Metabolomic studies among species and genotypes subjected to UV-B have revealed different phenolic compositions and de novo synthesis of molecules (Casati et al. 2011, Kusano et al. 2011). In this context, it has been suggested that among flavonoids, the flavonols subclass is the main group induced under UV-B radiation (Pollastri and Tattini 2011, Zoratti et al. 2014). In general, flavonoids have a strong UV-B absorbance capacity and relatively high antioxidant capacity depending on their structure (Rice-Evans et al. 1996). Nevertheless, some authors assign a major role to this group as UV-B absorbing or photoprotective compounds (Li et al. 1993, Bieza and Lois 2001).

Moreover, as a complement to the role of the UV-B absorbing compounds Phe and FL along with other plant secondary metabolites act as antioxidants through the scavenging of ROS (Rice-Evans et al. 1995, Pietta 2000). According to Solovchenko and Merzlyak (2008) this is a tolerance mechanism. The ROS scavenging capacity (RSC) is primarily attributed to the hydroxyl substituents of Phe and FL, conferring antioxidant, chelating and prooxidant activity (Heim et al. 2002). Nonetheless, flavonoids are often found as glycosylated derivatives in plants, which negatively influences their RSC (Pietta 2000). In addition to the non-enzymatic antioxidant strategies detailed above, enzymatic antioxidants such as superoxide dismutase (SOD) is also involved in UV-B protection in plants. According to Hideg et al. (2002), the dominant ROS produced under UV-B stress is the anion superoxide $\left(\mathrm{O}_{2}^{-}\right)$, which is scavenged by SOD. It has been reported that SOD activity varied among plants 
species according to the UV-B dose applied (Agrawal et al. 2009).

South-central Chile, an important agricultural region, has increased levels of UV-B radiation because of the decreasing ozone layer (Huovinen et al. 2006). Thus, many crops are cultivated under high UV-B radiation as is the case of highbush blueberry (Vaccinium corymbosum). The high antioxidant attributes of its fruits, as well as its high economic returns, have positioned the blueberry as an important crop in this region (Ribera et al. 2010). Our previous studies have shown different capacities of cultivars to respond to the abiotic stresses such as aluminum and manganese toxicities frequently found in south-central Chile (Reyes-Díaz et al. 2009, 2010, Rojas-Lillo et al. 2014). In these studies, we demonstrated that some $V$. corymbosum cultivars showed contrasting behavior under these abiotic constrains, with Legacy being considered a resistant and Bluegold a sensitive cultivar. However, information about metabolic and antioxidant strategies affected by UV-B radiation in $V$. corymbosum cultivars is still limited. Thus, the present work aimed to determine the effect of increasing doses of UV-B radiation in a long-term treatment in $V$. corymbosum cultivars and evaluate the strategy to counteract the negative effects of this stress. Therefore, plant growth, photosynthetic performance, antioxidants, photoprotective compounds accumulation, lipid peroxidation and metabolic responses to UV-B stress of Legacy and Bluegold were analyzed.

\section{Materials and methods}

\section{Plant material and experimental conditions}

In this work, two highbush blueberry ( $V$. corymbosum) cultivars (Legacy and Bluegold) frequently cultivated in south-central Chile were used. The 2-year-old clone plants were provided by Berries San Luis in south-central Chile $\left(38^{\circ} 29^{\prime} \mathrm{S}, 72^{\circ} 23^{\prime} \mathrm{W}\right)$, transported to the Universidad de la Frontera $\left(38^{\circ} 44^{\prime} \mathrm{S}, 72^{\circ} 37^{\prime} \mathrm{W}\right)$ and acclimated for 3 months under greenhouse conditions. Prior to the UV-B application, plants were conditioned by washing the roots carefully and placing them in $3 \mathrm{I}$ pots containing an Andisol (volcanic ash soil), a soil substrate typical of the region where this species is cultivated. The soil was previously analyzed for its chemical composition (organic matter, $\mathrm{pH}$, available $\mathrm{P}, \mathrm{S}$ and $\mathrm{N}$, exchangeable $\mathrm{Al}, \mathrm{Mn}, \mathrm{Mg}, \mathrm{Ca}, \mathrm{K}$ and $\mathrm{Na}$ ) according to Sadzawka et al. (2004). Based on the chemical analyzes, soil was fertilized according to the agronomic fertilization for blueberry plants. Thus, the NPK (Nitrogen, Phosphorus, Potassium) ratio of 2:1:1 (3:1.5:1.5 $\mathrm{g} \mathrm{m}^{-2}$; Hancock and Hanson, 1986) was applied by fertigation for 1 month of pre-UV-B treatments.

\section{Greenhouse irradiation conditions}

Three irradiation conditions were used in this study: (1) photosynthetically active radiation (PAR) irradiation without UV-B exposure (-UV-B), (2) PAR plus UV-B, simulating a typical winter daily course of UV-B radiation, which corresponds to low UV-B radiation and (3) PAR plus UV-B simulating a summer daily course of radiation which corresponds to a $30 \%$ increase in UV-B intensity over the typical irradiance of UV-B in south-central Chile (De los Rios et al., 2007, De los Rios and Acevedo, 2010). The UV-B radiation was applied via UV-B Q-lamps (Q-Panel 313; Cleveland, Ohio) enclosed in a cellulose diacetate $(0.08 \mathrm{~mm})$ filter to remove UV-C radiation from the lamps (Middleton and Teramura 1993). Under this condition, the transmitted photon flux energy was $57 \%$ of the total UV-B and only $5.7 \%$ UV-A radiation. Thus, it was possible to ensure that the UV radiation applied in this study was mainly biologically effective UV-B. The Q-lamps were suspended $20 \mathrm{~cm}$ above the top of plant. The UV-B daily course was carried out automatically by setting individual timers (mod. Temps $24 \mathrm{H}$, Halux ${ }^{\circledR}$, Santiago, Chile) on each Q-lamp to obtain 2.5 and $5.2 \mathrm{~W} \mathrm{~m}^{-2} \mathrm{UV}$-B irradiance $\left(63.0\right.$ and $128.7 \mathrm{~kJ} \mathrm{~m}^{-2}$ day ${ }^{-1}$ UV-B daily dose, respectively). The biologically effective UV-B (UV-B $B_{B E}$ irradiance) was 0.07 and $0.19 \mathrm{~W} \mathrm{~m}^{-2}$ for low and high UV-B treatments, respectively (Fig. S1, Supporting Information). The UV-B radiation range was 280 to $320 \mathrm{~nm}$ and measured with a spectroradiometer (Li-COR ${ }^{\circledR} 1800$, Lincoln, NE). Daily PAR radiation was followed with Li-COR Li-189, with sensor Quantum Nº Q32496 (Lincoln, NE). Measurements were taken during the day above the plants tops. The daily PAR was on average $400 \mu \mathrm{mol}$ photons $\mathrm{m}^{-2} \mathrm{~s}^{-1}$ day ${ }^{-1}$. All the experiments were performed simultaneously in greenhouse and PAR conditions were the same for all the UV-B levels simulated.

During the assay, the plants were maintained at $24^{\circ} \mathrm{C}$ $\left( \pm 2^{\circ} \mathrm{C}\right)$, relative humidity of $75 \%( \pm 5 \%)$, a photoperiod of $16 \mathrm{~h} \mathrm{light}$ and $8 \mathrm{~h}$ dark. Irrigation was performed every day to maintain water field capacity. The plants remained under different UV-B doses for 7, 14 and 21 days. To minimize any positional effect, the placement of pots with plants was changed randomly every day.

A completely randomized experimental $2 \times 3 \times 3$ design (two blueberry cultivars, three UV-B treatments and three time periods) was used with three replicates per treatment. The experimental units consisted of one plant per pot, giving a total of 54 pots for the assay. Measurements were taken at the beginning of the light period on each harvesting day. Samples were collected from fully expanded leaves from the first upper third top 
of the plant, immediately frozen in liquid nitrogen and stored at $-80 \mathrm{C}$ for biochemical analyzes.

\section{Plant growth parameters}

Plant growth was determined by measuring the shoot height (from the root collar to the end of selected branches) at the beginning and end of the experiment. Relative growth rate (RGR) was determined from the mean natural logarithm-transformed plant heights $\left(\operatorname{lnH}_{2}\right)-\left(\operatorname{lnH}_{1}\right) /\left(t_{2}-t_{1}\right)$, where $t_{1}$ and $t_{2}$ are the times 0 and 21 days, respectively as described by Hoffmann and Poorter (2002).

\section{Epidermis and mesophyll autofluorescence using confocal laser scanning microscopy}

Autofluorescence in different sections of fresh leaves of epidermal and mesophyll tissue of $V$. corymbosum cultivars was examined early (7 days) using confocal laser scanning microscopy (CLSM, Olympus FV1000, Olympus Co., Tokyo, Japan). Cross-sections of leaf tissues were cut using a double-sided razor blade, mounted in water and then observed. The $488 \mathrm{~nm}$ line of an $\mathrm{Ar}$ ion laser and $633 \mathrm{~nm}$ of a He-Ne laser were used for excitation. A beam splitter (HFT UV/488/633; Olympus Co.) was used to separate excitation from emission and to divide the fluorescence emission into two channels. The chloroplast autofluorescence $(633 \mathrm{~nm}$ excitation) was visualized at $650-750 \mathrm{~nm}$ with a long-pass filter. Phenolic compounds autofluorescence ( $488 \mathrm{~nm}$ excitation) were visualized at $530 \mathrm{~nm}$ (Kolb et al. 2001, Agati et al. 2009). Images were processed using image processing software (software FLUOVIEW FV10-ASW v0.200c; Olympus Co.).

\section{Measurement of photosynthetic parameters}

Carbon dioxide $\left(\mathrm{CO}_{2}\right)$ assimilation was measured in intact fully expanded leaves belonging to the first upper third of non-flowering plants with a portable photosynthesis system (LI-6400, LI-COR Inc., Lincoln, NE) controlling for light $\left(300 \mu \mathrm{mol}\right.$ photons $\left.\mathrm{m}^{-2} \mathrm{~s}^{-1}\right)$, temperature $\left(20^{\circ} \mathrm{C}\right)$, humidity $(80 \%)$ and $\mathrm{CO}_{2}(360 \mathrm{ppm})$ as described earlier by Reyes-Díaz et al. (2011). Measurements were taken on the morning of each collection day. The chlorophyll a fluorescence analyzes were determined by using a portable pulse-amplitude modulated fluorimeter (FMS 2; Hansatech Instruments, King's Lynn, UK), exactly as described by Reyes-Díaz et al. (2009, 2010). The maximum quantum yield (Fv/Fm), effective quantum yield ( $\Phi P S I I)$, electron transport rate (ETR) and non-photochemical quenching (NPQ) were calculated according to Maxwell and Johnson (2000).

\section{Photosynthetic pigments}

Chlorophyll and carotenoids were extracted from leaves with $100 \% \mathrm{v} / \mathrm{v}$ acetone (HPLC grade) and analyzed according to García-Plazaola and Becerril (1999), using a high-performance liquid chromatography (HPLC) system (Agilent technologies 1200 series, column C-18 Waters spherisorb $5.0 \mu \mathrm{m}$ ODS1 $4.6 \times 250 \mathrm{~mm}$ ). Standards for the pigments $V x, A x, Z x$, neoxanthin $(N x)$, chlorophyll (Chl) $a, b, \beta$-carotene $(\beta \mathrm{Ca})$ and lutein (Lt) were purchased from Sigma-Aldrich (Sigma Chemical Co. St. Louis, MO). The de-epoxidation state of the xanthophyll-cycle pigments (DEPS) was calculated as described by Klem et al. (2015).

\section{Chloroplast isolation and ROS determination using flow cytometry}

Chloroplasts were isolated from leaf samples as described by Grabsztunowicz and Jackowski (2012). Later on, intracellular ROS production was determined according to Maxwell et al. (1999) with modifications. The suspension of intact chloroplasts was incubated at $37^{\circ} \mathrm{C}$ for $30 \mathrm{~min}$ with the fluorescent probe chloromethyl 2',7'-dichlorodihydrofluorescein diacetate $\left(\mathrm{CM}-\mathrm{H}_{2}\right.$ DCFDA) (Invitrogen, Molecular Probes ${ }^{\mathrm{TM}}$, Eugene, OR, USA). The chloroplast ROS production was analyzed using flow cytometry (Becton Dickinson ${ }^{\mathrm{TM}}$, Becton Dickinson, San Jose, CA, USA). All measurements were taken using an $\mathrm{Ar}$ ion laser excited at $488 \mathrm{~nm}$ and emitting at $530 \mathrm{~nm}$. The images were processed through the FACSDiva 6.1.3 software (Becton Dickinson $^{\mathrm{TM}}$ ). Autofluorescence of chloroplasts was measured and then a positive control (intact chloroplasts plus $\mathrm{H}_{2}$ DCFDA and $100 \mu M \mathrm{H}_{2} \mathrm{O}_{2}$ ) and a negative control (intact chloroplasts plus $\mathrm{H}_{2}$ DCFDA without $\mathrm{H}_{2} \mathrm{O}_{2}$ ) were assessed (Rabinovitch 2001). Chloroplasts testing positive for ROS fluorescence related to the entire chloroplast population per sample were evaluated.

\section{Determination of ROS in leaf extracts}

ROS levels in total leaf extracts were determined as described by Jambunathan (2010) using $\mathrm{CM}-\mathrm{H}_{2}$ DCFDA as the ROS-specific probe (Invitrogen, Molecular Probes). The dye $\mathrm{CM}-\mathrm{H}_{2}$ DCFDA has absorption at $492-495 \mathrm{~nm}$ and maximum emission at $517-527 \mathrm{~nm}$. Fluorescence detection was carried out on a Synergy ${ }^{\mathrm{TM}}$ HT multimode microplate reader (Bio-Tek Instruments, Winooski, VT).

\section{Lipid peroxidation and antioxidant activity}

As an oxidative stress indicator, the lipid peroxidation (LP) of membranes through malondialdehyde (MDA) 
was determined in fresh material using a thiobarbituric acid reacting substances (TBARS) assay according to the modified method of Du and Bramlage (1992). The absorbance was measured at 532, 600 and $440 \mathrm{~nm}$. The radical scavenging activity was determined using the method of oxygen radical antioxidant capacity (ORAC) described by $\mathrm{Ou}$ et al. (2001) adapted for a 96-well plate (Roy et al. 2010). Leaves were extracted with $80 \%$ ethanol and measured in their antioxidant capacity to inhibit the decline of fluorescence induced by the radical generator 2,2'-azobis (2-amidinopropane) dihydrochloride (AAPH). Oxygen radical absorbance capacity values were calculated as the integrated peak area under the decay curve (AUC) between the blank and a sample. The values were expressed as micromoles of Trolox equivalents (TE) per gram of fresh weight.

\section{Total phenols, flavonoids and anthocyanins}

Total soluble phenols (TP) contained in ethanolic extracts were determined with Folin-Ciocalteu reagent by the method described by Slinkard and Singleton (1977) using chlorogenic acid as the standard. The extracts were measured spectrophotometrically at $765 \mathrm{~nm}$ (UV-VIS Spectrophotometer T80+, PG Instruments, Beijing, China). For total anthocyanins (TA), leaf samples were extracted with acidic ethanol solution $(1 \%)$ and measured in a spectrophotometer (UV-VIS Spectrophotometer T80+, PG Instruments, Beijing, China) at 530 and $657 \mathrm{~nm}$ using a molar extinction coefficient of cyanidin-3-glucoside (Sigma Chemical Co. St. Louis, MO). Results were expressed as milligrams of cyanidin-3-glucoside equivalents per fresh weight (Strack and Wray 1989). Total flavonoids (TFs) were measured by the aluminum chloride colorimetric assay as described by Zhishen et al. (1999) with some modifications using rutin as the standard (Sigma Chemical Co.). Samples were measured spectrophotometrically at $510 \mathrm{~nm}$ (UV-VIS Spectrophotometer T80+, PG Instruments). The results were expressed as milligrams of rutin equivalents per gram of fresh weight.

\section{Total soluble UV-B absorbing compounds}

The UV-B absorbing capacity of leaves was determined under UV-B conditions as described by Semerdjieva et al. (2003). Briefly, leaf samples from each cultivar were frozen in liquid nitrogen, ground and extracted with methanol for $1 \mathrm{~h}$ at room temperature in the dark and centrifuged at $16000 \mathrm{~g}$ for $15 \mathrm{~min}$. The supernatant was removed and the pellet was re-suspended with methanol and re-extracted twice for 30 and $10 \mathrm{~min}$, respectively. Supernatants were pooled and stored at $4^{\circ} \mathrm{C}$ and spectrophotometrically measured from 250 to $400 \mathrm{~nm}$. The UV absorbing compounds (UAC) were normalized to $284 \mathrm{~nm}$ according to Semerdjieva et al. (2003) and Clarke and Robinson (2008) and the integration of AUC was performed from 280 to $320 \mathrm{~nm}$. Results were expressed as AUC per mg fresh weight and per leaf area in centimeter square.

\section{Phenylpropanoid profile}

Phe and FL composition analyses were performed using HPLC coupled with a mass detector (HPLC-MS) according to Lin and Harnly (2007). Leaves were extracted with methanol $80 \% \mathrm{v} / \mathrm{v}$. The applied system was an HPLC Shimadzu Prominence coupled to a mass spectrometer MDS Sciex 3200 Qtrap ${ }^{\circledR}$ (Applied Biosystems) with electrospray ionization Turbo VTM at $450^{\circ} \mathrm{C}$. The chromatographic separation was done with an RP-C18 Inertsil ${ }^{\circledR}$ ODS-3 column $(2.1 \times 150 \mathrm{~mm}, 3 \mu \mathrm{m}$; GL Sciences Inc., Tokyo, Japan), an injection volume of $10 \mu \mathrm{l}$, $0.2 \mathrm{ml} \mathrm{min}^{-1}$ flux, a constant column temperature of $35^{\circ} \mathrm{C}$ and a mobile phase at different concentration gradients of formic acid $0.1 \% \mathrm{v} / \mathrm{v}$ and methanol. The equipment control and post hoc analysis were done with software Analyst 1.5.1 (AB SCIEX, Ontario, Canada).

\section{Statistical analyzes}

All data passed the normality and equality of variance tests after the Kolmogorov-Smirnov test. Data were subjected to a two-way ANOVA where the factors were cultivar and UV-B treatment. A Tukey's significant differences test identified those values with significant differences $(P<0.05)$. Analyzes were performed with Sigma Stat 3.5 (SYSTAT Software Inc.).

Three correlation matrices were performed for each species at each collection point (7, 14 and 21 days) among the three UV-B light irradiances with all parameters. Correlations were calculated from mean data for an accession across all replicates and experiments. The original data are given in the Supplementary section (Table S3). Significance levels were $P<0.05$. For Pearson's correlation coefficients and $P$-value data, GraphPad Prism 6 was used and a matrix design was generated using Microsoft Office Excel ${ }^{\circledR}$.

\section{Results}

\section{Growth, photosynthetic performance and oxidative stress under contrasting UV-B radiation levels}

Plant height was measured to determine RGR. This parameter was reduced by both UV-B doses where the 
Table 1. Relative growth rates of plants from two $V$. corymbosum cultivars growing under different UV-B doses for 21 days. Values represent averages of three biological replicates \pm SE. Different capital letters indicate significant differences $(P \leq 0.05)$ between cultivars for the same treatment. Different lowercase letters show differences $(P \leq 0.05)$ between treatments for the same cultivar.

\begin{tabular}{lcc}
\hline Cultivar & $\begin{array}{c}\text { UV-B treatment } \\
\left(\mathrm{W} \mathrm{m}^{-2}\right)\end{array}$ & $\begin{array}{c}\text { Relative growth rate } \\
\left.\text { [mean } \pm \text { SE }\left(\mathrm{mm} \mathrm{day}^{-1}\right)\right]\end{array}$ \\
\hline Legacy & Control & $0.032 \pm 0.006 \mathrm{Ab}$ \\
& 0.07 & $0.012 \pm 0.003 \mathrm{Aa}$ \\
Bluegold & 0.19 & $0.009 \pm 0.004 \mathrm{Aa}$ \\
& Control & $0.038 \pm 0.006 \mathrm{Ab}$ \\
& 0.07 & $0.011 \pm 0.005 \mathrm{Aa}$ \\
0.19 & $0.013 \pm 0.005 \mathrm{Aa}$ \\
\hline
\end{tabular}

decrease was around $69 \%$ for $0.19 \mathrm{~W} \mathrm{~m}^{-2}$ compared with the control treatment (Table 1). Surprisingly, no differences were observed between the Legacy and Bluegold cultivars.

Considering that RGR decreased after UV-B treatments in both cultivars, we decided to investigate whether the UV-B levels would lead to an altered photosynthetic rate (Table 2). Thus, we observed that the $\mathrm{CO}_{2}$ assimilation rate was different between the two cultivars, with higher values for Legacy. This cultivar displayed a constant $\mathrm{CO}_{2}$ assimilation rate at all UV-B levels and time periods (Table 2). In contrast, under high UV-B dose, Bluegold showed a strong decrease in the $\mathrm{CO}_{2}$ assimilation rate from the 7 th day, which was statistically significant at 14th and 21st day of treatment compared with the control treatment (Table 2). Interestingly, transpiration rates were not affected by either UV-B or by exposure time to UV-B in either cultivar (Table 2).

The measurement of chlorophyll a fluorescence parameters indicated that $\mathrm{Fv} / \mathrm{Fm}, \phi \mathrm{PSII}$ and ETR in Legacy and Bluegold plants did not differ compared with the control plants on either level of UV-B for all time periods (Table 2). Non-photochemical quenching decreased in both cultivars at the high UV-B intensity at all time points, the differences of which were higher at 21 days of treatment. Nonetheless, at low UV-B radiation, only Legacy decreased its values compared with the control (Table 2).

In order to obtain information about the effect of UV-B exposure on carotenoid levels, the concentration of these pigments was measured. In general, the carotenoid pool showed a contrasting trend (Fig. 1). For Legacy, a decrease was found under UV-B radiation from the second week of treatment, whereas Bluegold showed an increase. The levels of $\beta \mathrm{Ca}$ and $\mathrm{Lt}$, which is derived from $\alpha$-carotene, increased around $20 \%$ in
Bluegold plants under high UV-B doses at 21 days compared with the control treatment (Fig. 1B). Antheraxanthin and Zx decreased in Legacy under high UV-B exposure (Fig. 1A), whereas in Bluegold Ax levels remained constant (Fig. 1B), whereas $V x$ was increased by UV-B radiation in both cultivars (Fig. 1). The de-epoxidation state (DEPS) indicates the flux of xanthophyll carotenoids toward de-epoxidation of $V x$ via $A x$ to $Z x$. DEPS in Legacy was reduced by the high UV-B radiation at all measured time points compared with the control $(P<0.05 ;$ Fig. 1). Meanwhile, no changes were found at low UV-B radiation; these values were similar to the control. For Bluegold, a similar reduction in DEPS by UV-B radiation was found with respect to untreated plants $(P<0.05)$, and this occurred at lower UV-B dose than for Legacy. On the other hand, $\mathrm{Chl}$ concentrations and ratio were not affected at any time and dose of UV-B radiation of either cultivar (Table S1).

In general, Bluegold presented greater ROS values than Legacy in isolated chloroplasts from UV-B-treated plants compared with untreated plants. The highest ROS level (11-fold higher than control) was exhibited by Bluegold after 7 days of UV-B treatment at low UV-B radiation compared with untreated plants (Fig. 2A). Interestingly, from the 14th to 21 st days of UV-B exposure, the differences were smaller (approximately onefold) than at 7 days, but still significant. For Legacy, at the highest UV-B dose, an increase in ROS (twofold) was observed at each time point compared with the control (Fig. 2A). In addition, total ROS produced in leaves did not change at all times points by applying different UV-B treatments in Legacy (Fig. 2B). In contrast, Bluegold showed an increase in ROS accumulation from the 14th day of treatment at the highest UV-B dose. At the end of the experiment, Bluegold showed higher ROS at both UV-B treatments compared with the control (88 and 162\%, respectively; Fig. 2B).

The levels of LP for Bluegold increased at 21 days of UV-B treatment (Fig. 2C). In contrast, LP was enhanced in Legacy with the low dose of UV-B radiation after 7 days of treatment, decreasing thereafter (14th and 21st days) at both UV-B doses (Fig. 2C).

\section{Leaf tissue visualization using confocal microscopy and accumulation of UV-B screening compounds}

To visualize the impact of UV-B on leaves, we used confocal microscopy to compare Legacy and Bluegold leaf tissue without treatment and after 7 days of exposure to UV-B radiation. Interestingly, bronzing of Legacy leaves subjected to the high dose of UV-B was observed, whereas in Bluegold, this effect was less pronounced. In response to UV-B treatment, Legacy epidermis cells 
Table 2. Gas exchange and chlorophyll a fluorescence parameters measured in fully expanded leaves from plants of two $V$. corymbosum cultivars growing under different UV-B doses. Data are means of three biological replicates \pm SE. Different lowercase letters indicate statistically significant differences among treatments for the same cultivar and exposure time (Tukey's HSD at $P \leq 0.05$ ). Different uppercase letters indicate differences (Tukey's HSD at $P \leq 0.05$ ) between cultivars for the same exposure time and treatment. Asterisks (*) indicate statistically significant differences at $P \leq 0.001$.

\begin{tabular}{|c|c|c|c|c|c|c|c|}
\hline & \multirow[b]{2}{*}{$\mathrm{T}$ (days) } & \multicolumn{3}{|c|}{ Legacy } & \multicolumn{3}{|c|}{ Bluegold } \\
\hline & & Control & $0.07 \mathrm{~W} \mathrm{~m}^{-2}$ & $0.19 \mathrm{Wm}^{-2}$ & Control & $0.07 \mathrm{~W} \mathrm{~m}^{-2}$ & $0.19 \mathrm{~W} \mathrm{~m}^{-2}$ \\
\hline \multirow{3}{*}{$\mathrm{CO}_{2}$ assimilation $\left(\mu \mathrm{mol} \mathrm{CO}_{2} \mathrm{~m}^{-2} \mathrm{~s}^{-1}\right)$} & 7 & $2.10 \pm 0.12 \mathrm{aB}$ & $2.10 \pm 0.10 \mathrm{aB}$ & $2.03 \pm 0.05 \mathrm{aB}$ & $1.71 \pm 0.13 \mathrm{bA}$ & $1.62 \pm 0.15 b A$ & $1.27 \pm 0.11 \mathrm{aA}$ \\
\hline & 14 & $2.06 \pm 0.1 \mathrm{aB}$ & $2.10 \pm 0.03 \mathrm{aB}$ & $2.00 \pm 0.21 \mathrm{aB}$ & $1.62 \pm 0.19 b A$ & $1.60 \pm 0.19 b A$ & $0.55 \pm 0.06 \mathrm{aA}$ \\
\hline & 21 & $2.00 \pm 0.06 \mathrm{aB}$ & $2.06 \pm 0.13 \mathrm{aB}$ & $2.01 \pm 0.10 a B$ & $1.63 \pm 0.11 \mathrm{bA}$ & $1.60 \pm 0.10 b A$ & $0.66 \pm 0.05 a A$ \\
\hline \multirow[t]{3}{*}{ Transpiration rate $\left(\mathrm{mmol} \mathrm{H}_{2} \mathrm{O} \mathrm{m}^{-2} \mathrm{~s}^{-1}\right)$} & 7 & $1.53 \pm 0.06 a \mathrm{~A}$ & $1.54 \pm 0.11 \mathrm{aA}$ & $1.58 \pm 0.07 a A$ & $1.40 \pm 0.06 a \mathrm{~A}$ & $1.50 \pm 0.04 a A$ & $1.50 \pm 0.04 a \mathrm{~A}$ \\
\hline & 14 & $0.83 \pm 0.00 \mathrm{aA}$ & $0.86 \pm 0.01 \mathrm{aA}$ & $0.86 \pm 0.01 \mathrm{aB}$ & $0.84 \pm 0.01 \mathrm{bA}$ & $0.82 \pm 0.01 \mathrm{abA}$ & $0.8 \pm 0.01 a A^{*}$ \\
\hline & 21 & $0.83 \pm 0.01 \mathrm{aA}$ & $0.82 \pm 0.02 \mathrm{aA}$ & $0.81 \pm 0.00 a \mathrm{~A}$ & $0.86 \pm 0.01 \mathrm{bA}$ & $0.84 \pm 0.00 \mathrm{bA}$ & $0.8 \pm 0.01 \mathrm{aA}$ \\
\hline \multirow[t]{3}{*}{$\mathrm{Fv} / \mathrm{Fm}$} & 7 & $0.84 \pm 0.01 \mathrm{aA}$ & $0.87 \pm 0.01 \mathrm{aA}$ & $0.84 \pm 0.01 \mathrm{aA}$ & $0.86 \pm 0.01 \mathrm{aA}$ & $0.85 \pm 0.01 \mathrm{aA}$ & $0.83 \pm 0.00 a A$ \\
\hline & 14 & $0.83 \pm 0.00 \mathrm{aA}$ & $0.86 \pm 0.01 \mathrm{aA}$ & $0.86 \pm 0.01 \mathrm{aB}$ & $0.84 \pm 0.01 \mathrm{bA}$ & $0.82 \pm 0.01 \mathrm{abA}$ & $0.80 \pm 0.01 \mathrm{aA}$ \\
\hline & 21 & $0.83 \pm 0.01 \mathrm{aA}$ & $0.82 \pm 0.02 \mathrm{aA}$ & $0.81 \pm 0.00 a \mathrm{~A}$ & $0.86 \pm 0.01 \mathrm{bA}$ & $0.84 \pm 0.00 \mathrm{bA}$ & $0.80 \pm 0.01 a A$ \\
\hline \multirow[t]{3}{*}{ ФPSII } & 7 & $0.24 \pm 0.01 \mathrm{abA}$ & $0.22 \pm 0.01 \mathrm{aA}$ & $0.27 \pm 0.01 \mathrm{bA}$ & $0.23 \pm 0.01 \mathrm{aA}$ & $0.23 \pm 0.0 \mathrm{aA}$ & $0.22 \pm 0.01 \mathrm{aA}$ \\
\hline & 14 & $0.23 \pm 0.01 \mathrm{aA}$ & $0.23 \pm 0.02 \mathrm{aA}$ & $0.26 \pm 0.02 a \mathrm{~A}$ & $0.2 \pm 0.00 \mathrm{aA}$ & $0.23 \pm 0.01 \mathrm{aA}$ & $0.22 \pm 0.02 \mathrm{aA}$ \\
\hline & 21 & $0.26 \pm 0.01 \mathrm{aA}$ & $0.26 \pm 0.01 \mathrm{aA}$ & $0.23 \pm 0.01 \mathrm{aA}$ & $0.23 \pm 0.01 \mathrm{aA}$ & $0.24 \pm 0.01 a A$ & $0.18 \pm 0.01 a A$ \\
\hline \multirow[t]{3}{*}{ ETR } & 7 & $30.3 \pm 0.93 a b A$ & $27.34 \pm 0.77 a A$ & $33.9 \pm 1.65 b B$ & $28.8 \pm 1.24 \mathrm{aA}$ & $28.4 \pm 0.31 \mathrm{aA}$ & $27.6 \pm 1.58 a A$ \\
\hline & 142 & $29.01 \pm 1.35 \mathrm{aA}$ & $29.34 \pm 0.48 a A$ & $32.6 \pm 2.77 a A$ & $27.9 \pm 0.33 a A$ & $29.0 \pm 1.45 a \mathrm{~A}$ & $27.7 \pm 2.22 \mathrm{aA}$ \\
\hline & 213 & $33.07 \pm 1.42 \mathrm{aA}$ & $33.02 \pm 1.52 \mathrm{aA}$ & $28.95 \pm 1.2 \mathrm{aA}$ & $29.0 \pm 1.21 \mathrm{aA}$ & $29.7 \pm 1.57 \mathrm{aA}$ & $23.2 \pm 1.53 a A$ \\
\hline \multirow[t]{3}{*}{ NPQ } & 7 & $3.26 \pm 0.04 a A$ & $2.73 \pm 0.1 \mathrm{aA}$ & $3.09 \pm 0.26 a A$ & $2.85 \pm 0.11 a A$ & $2.48 \pm 0.06 a A$ & $2.73 \pm 0.06 a A$ \\
\hline & 14 & $3.26 \pm 0.12 c A$ & $2.26 \pm 0.23 \mathrm{bA}$ & $1.75 \pm 0.18 a * A$ & $2.59 \pm 0.13 a b B$ & $3.07 \pm 0.09 \mathrm{bB}$ & $2.35 \pm 0.05 a B$ \\
\hline & 21 & $3.06 \pm 0.11 \mathrm{bA}$ & $1.79 \pm 0.47 a \mathrm{~A}$ & $1.47 \pm 0.1 \mathrm{aA}$ & $2.79 \pm 0.08 \mathrm{bA}$ & $2.78 \pm 0.11 \mathrm{bB}$ & $1.58 \pm 0.17 a A$ \\
\hline
\end{tabular}

exhibited higher levels of green fluorescence, corresponding to fluorescence of phenolic compounds, than Bluegold epidermal cells (Fig. S2). Green fluorescence was 27-fold higher than controls in Legacy, whereas in Bluegold this was 4.3-fold (Table S2). Red fluorescence, resulting from chlorophyll autofluorescence, is equally increased by UV-B treatment, but only slightly in both Legacy and Bluegold (1.3- and 1.5-fold, respectively) (Table S2). A disturbance was also observed in the autofluorescence of chloroplasts at the mesophyll level in Bluegold, suggesting a disruption in chloroplast integrity (Fig. S2B). Contrarily, this phenomenon was not observed in Legacy leaves (Fig. S2A).

\section{Antioxidant activity in leaves after UV-B radiation treatment}

To better understand the metabolic responses of plants exposed to UV-B radiation, several secondary metabolites were quantified. A significant interaction between cultivar and UV-B dose was observed for ORAC in Legacy at 14 and 21 days (Fig. 3A). There was a mild increase in ORAC in Legacy at 7 days under the highest dose of UV-B radiation, and after 14 days this increase was significantly higher with both UV-B radiation levels compared with the control. On the other hand, for Bluegold no change caused by the UV-B exposure was observed (Fig. 3A). In general, it was observed that UV-B radiation did not influence SOD activity in Legacy plants.
However, in Bluegold plants an increase in SOD activity was observed at the highest UV-B level on the 7 th and 21 st day (Fig. 3B).

\section{Accumulation of secondary metabolites involved in UV-B responses}

As compared with controls at the same time point, TP in Legacy increased as UV-B dose increased over the whole study period (Fig. 4A), with the highest TP accumulation, 1.7-fold over controls, being observed at 21 days under the highest UV-B dose. In contrast, Bluegold exhibited only minor changes in TP in response to UV-B, with the exception being on the 14th day at the highest UV-B dose, where a 1.7-fold increase in TP was observed (Fig. 4A).

The two cultivars displayed differential responses in terms of TA concentration under UV-B treatment (Fig. 4B). For Legacy, no change in TA was observed at either UV-B dose until 21 days of exposure, when TA levels were found to have decreased. In contrast, decay in TA levels was revealed in Legacy plants at 21 days of exposure to UV-B radiation (Fig. 4B). However, for Bluegold the opposite changes were observed over time: a significant increase in TA from the 14th to 21st days was observed at the highest UV-B dose (Fig. 4B).

In terms of TF accumulation, no difference was detected in Bluegold compared with the control at any UV-B treatment or any exposure time (Fig. 4C). In Legacy 


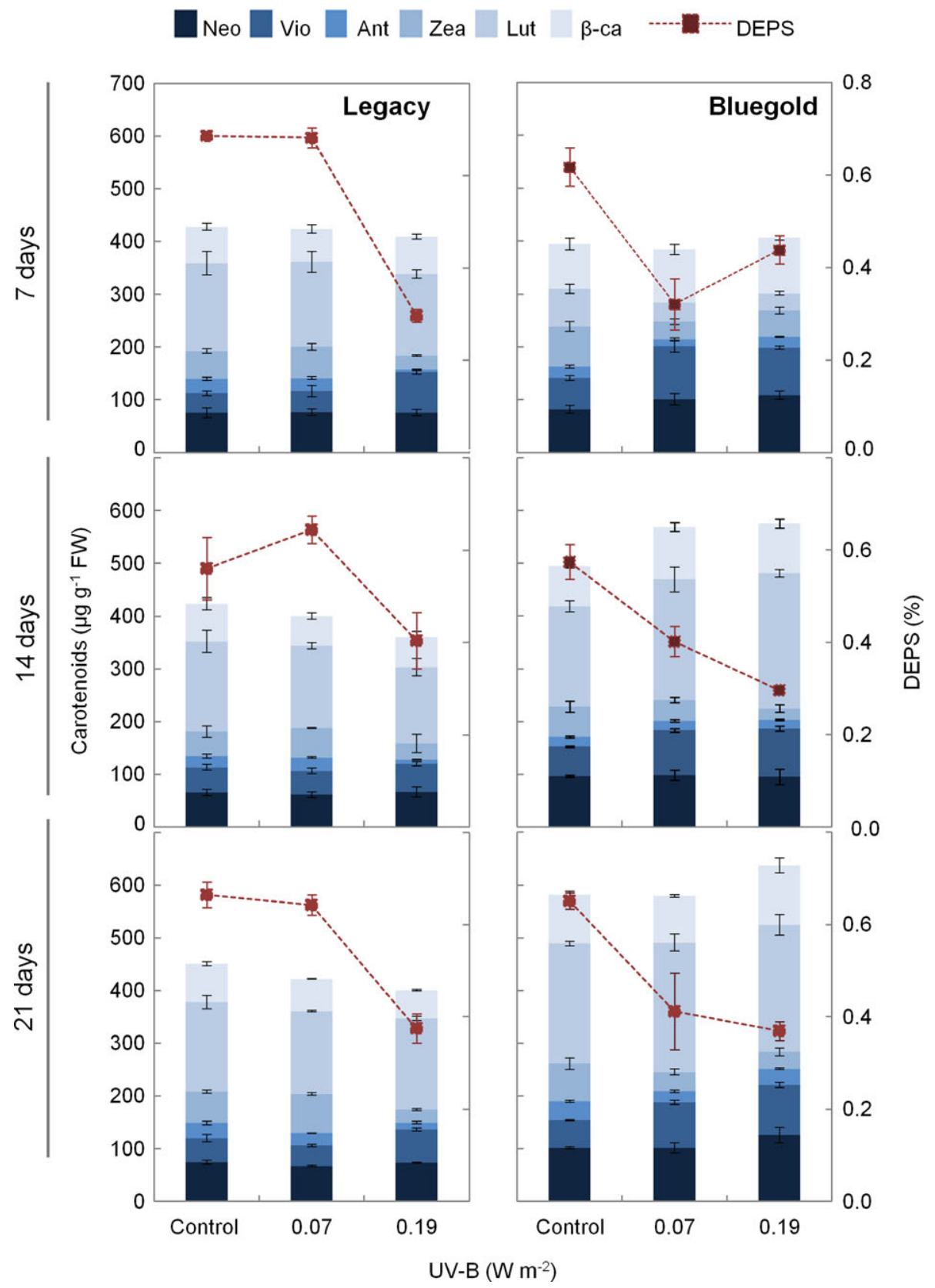

Fig. 1. Carotenoid pigments concentration $\left(\mu \mathrm{g} \mathrm{g}^{-1} \mathrm{FW}\right.$ ) and the nominal de-epoxidation state (DEPS) of the xanthophyll cycle pigments in leaves of plants from two highbush blueberry cultivars growing under control and UV-B radiation conditions. Values represent the average of three replicates $\pm \mathrm{SE}$. Ant, antheraxanthin; DEPS, de-epoxidation state of the xanthophyll-cycle pigments; Lut, lutein; Neo, neoxanthin; Vio, violaxanthin; Zea: zeaxanthin, $\beta$-ca: $\beta$-carotene.

a clear increase in TF was observed, around $71 \%$ at the highest UV-B dose at 7 days of treatment, then levels decreased by around $31 \%$ at 21 days with both UV-B doses (Fig. 4C).

Ultraviolet absorbing compounds showed an increase only for Legacy plants at the highest UV-B dose at 7 and 14 days of treatment compared with the control
(Fig. 4D). The major differences occurred at 14 days when there was an increase of about $92 \%$. At 21 days, AUC values in Legacy were lower, and were similar to those found in Bluegold across the experimental period (Fig. 4D).

Additionally, a phenolic profile at the end of the experiment was carried out considering only de novo 


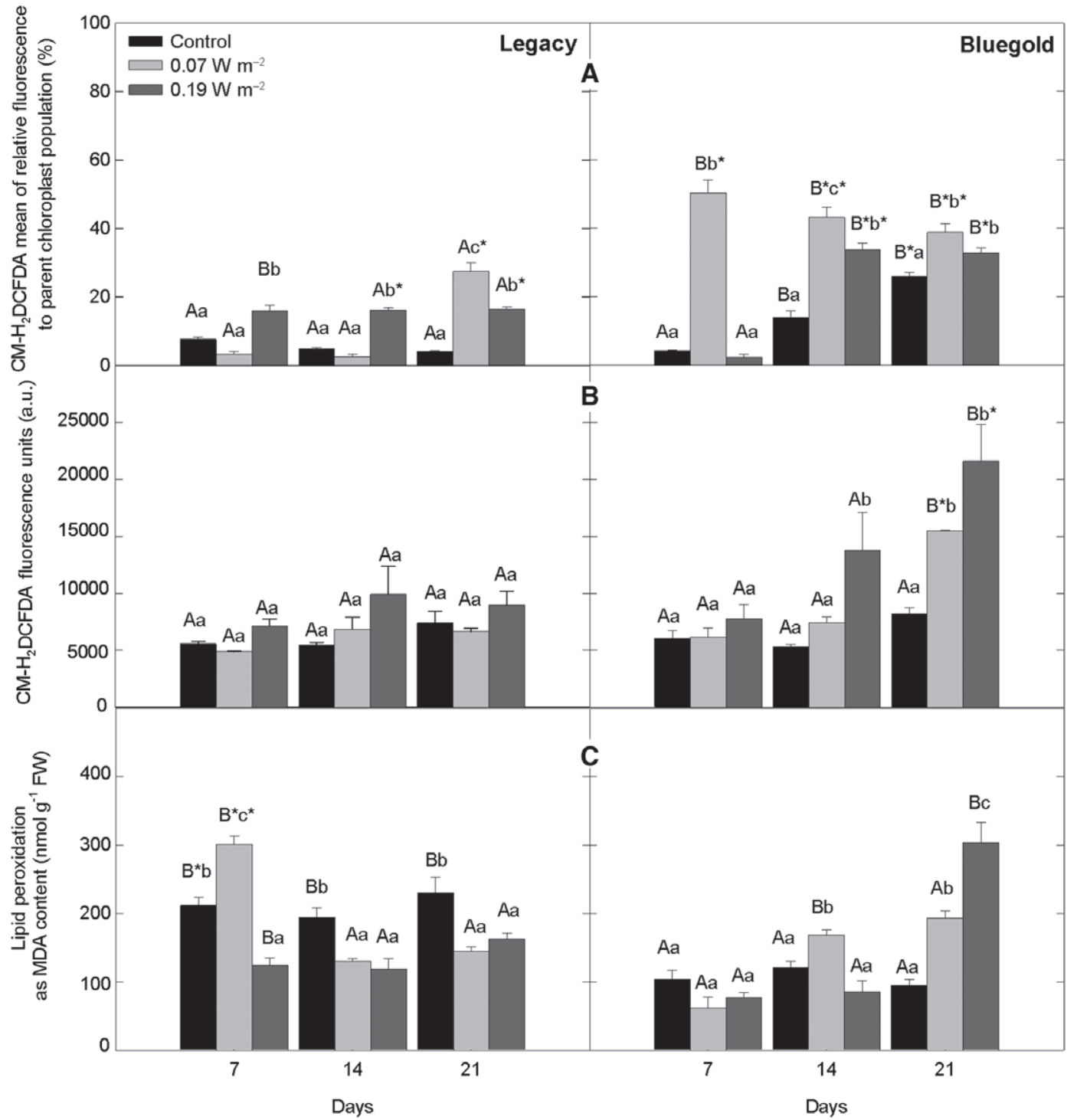

Fig. 2. ROS generation in chloroplasts of $V$. corymbosum plants under UV-B radiation conditions. Chloroplasts were stained with $10 \mu M$ of $\mathrm{CM}-\mathrm{H}_{2} \mathrm{CDFDA}$ dye and samples were incubated for $30 \mathrm{~min}$ at $37^{\circ} \mathrm{C}$. (A) ROS production in chloroplasts under UV-B treatments. (B) Total ROS. (C) Lipid peroxidation as malondialdehyde (MDA) concentration. All values represent the average of three replicates \pm SE. Different lower case letters indicate statistically significant differences (Tukey's HSD at $P \leq 0.05$ ) among treatments for the same cultivar and time. Different uppercase letters indicate differences (Tukey's HSD at $P \leq 0.05$ ) between cultivars for the same treatment and time.

phenolic compounds induced by the UV-B radiation treatments (Table 3). These compounds were not found in the control plants. A differential phenolic profile between the two cultivars was found, where Legacy showed a wider variety of induced compounds than the Bluegold plants under UV-B treatments (Table 3). Legacy synthesized mostly flavonol glycosides, such as quercetin-rhamnoside, kaempferol-glucoside and myricetin-xyloside. In general, all the induced compounds absorb strongly in the UV-B and UV-A ranges (Table S4).

\section{Correlation analysis between physiological and metabolic parameters}

To assess the level of association between the measured variables, Pearson's correlation coefficient was calculated for all pairs of measured parameters across the three UV-B radiation conditions (Fig. 5). At a level of 5\% significance, a total of 289 correlations were found, of which 171 were positive and 118 were negative. Differences were observed between the matrix correlations of 


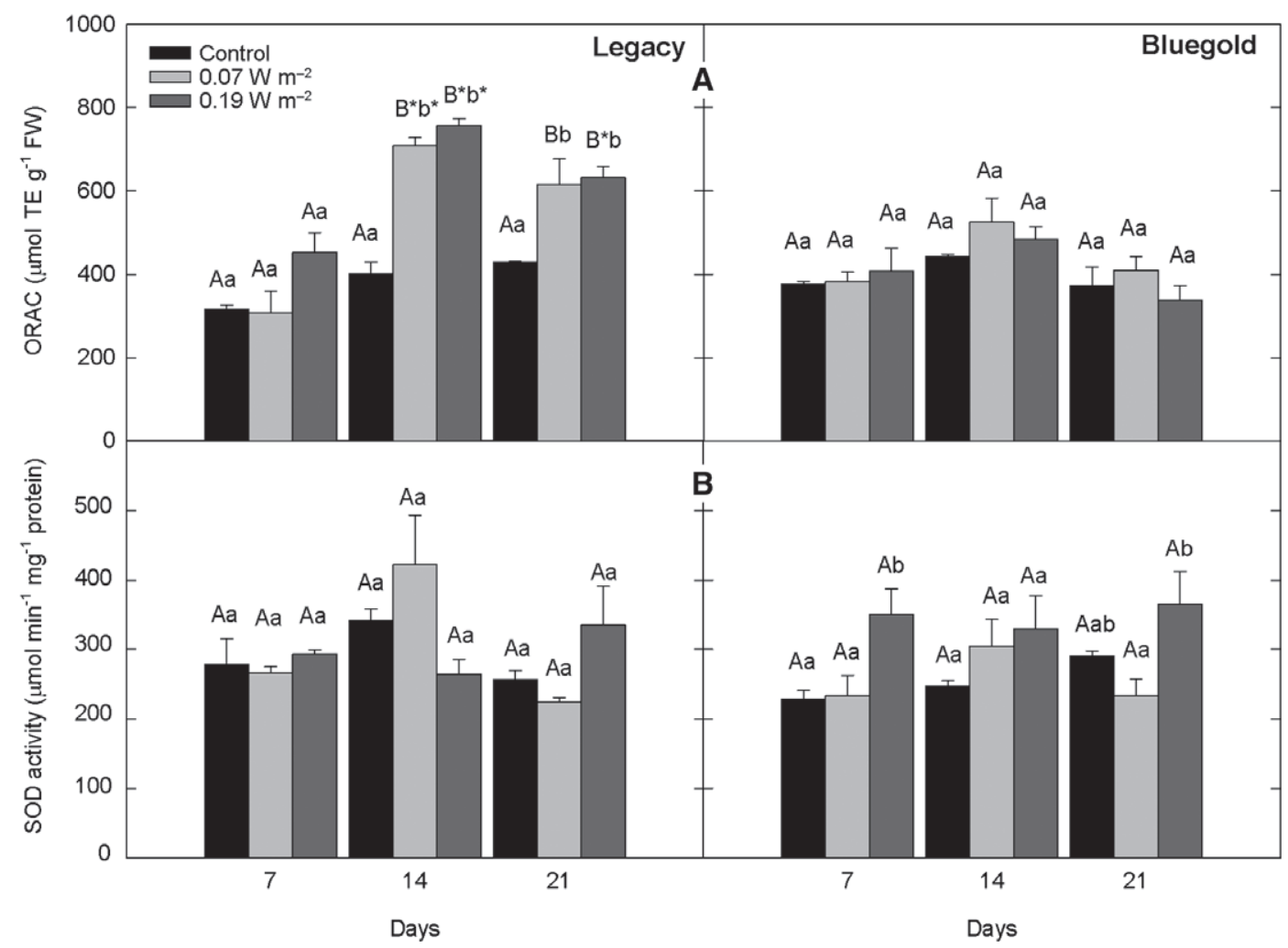

Fig. 3. Antioxidant capacity of leaves of $V$. corymbosum plants grown under different UV-B treatments. (A) Oxygen radical activity (ORAC) measured as Trolox equivalents (TE) and (B) Enzymatic antioxidant activity as superoxide dismutase (SOD). All values are the average of three replicates \pm SE. Different lowercase letters indicate statistically significant differences among treatments for the same cultivar and exposure time. Different uppercase letters indicate differences (Tukey's HSD at $P \leq 0.05$ ) between cultivars for the same exposure time and treatment.

the two cultivars (Fig. 5). As noted, Legacy activated a non-enzymatic antioxidant system at the onset of stress. As evidence, flavonoids were positive strongly correlated with total ROS and chloroplast ROS on the 7th day (Fig. 5A) and phenols strongly correlated with phenols with total ROS and chloroplast ROS on the 14th day (Fig. 5C). A positive correlation between ROS levels and phenolic compounds was observed only on the 21st day in Bluegold. After 7 days of treatment, negative correlations were found between LP and ROS produced in the chloroplast, total ROS levels, TF and Vx content, as well as $\phi$ PSII, ETR in Legacy (Fig. 5A). In the following days this behavior was not so evident, and most of the LP correlations were positive (Fig. 5C, E). Interestingly, Bluegold plants exhibited a different behavior. In this cultivar, it was observed that most of the physiological parameters at 21 days, such as $\mathrm{CO}_{2}$ assimilation and $\mathrm{Fv} / \mathrm{Fm}$, were negatively correlated with many of the other parameters, including LP, total ROS, TP, TA, Nx and Lt levels (Fig. 5F). This highlights the sensitivity of Bluegold to UV-B radiation in comparison with Legacy's tolerance to the same treatment.

\section{Discussion}

This study applied simulated UV-B radiation conditions on $V$. corymbosum cultivars for 3 weeks. We observed that although both cultivars were affected by UV-B radiation in terms of shoot growth, their plant performance was completely different. Previous studies have suggested that UV-B radiation alone and combined with manganese toxicity affects stem elongation in highbush blueberry (Rojas-Lillo et al. 2014). It has also been demonstrated that plant growth is strongly affected by UV-B radiation (Teramura and Sullivan 1994, Krizek et al. 1997, Conner and Neumeier, 2002, Kumari et al. 2009, Zhu and Yang 2015). One of the reasons for the reduced plant growth following UV-B exposure could be the reduction in photosynthetic performance as well as the amount of assimilates as observed in grape (Kolb et al. 2001) and rice (Mohammed and Tarpley 2010). In cucumber plants, an increase in stem elongation and growth under UV-B exclusion has been observed, showing that growth can be affected even at ambient levels of UV-B (Krizek et al. 1997, Kanungo et al. 2013). These effects are generally mild and are more pronounced 


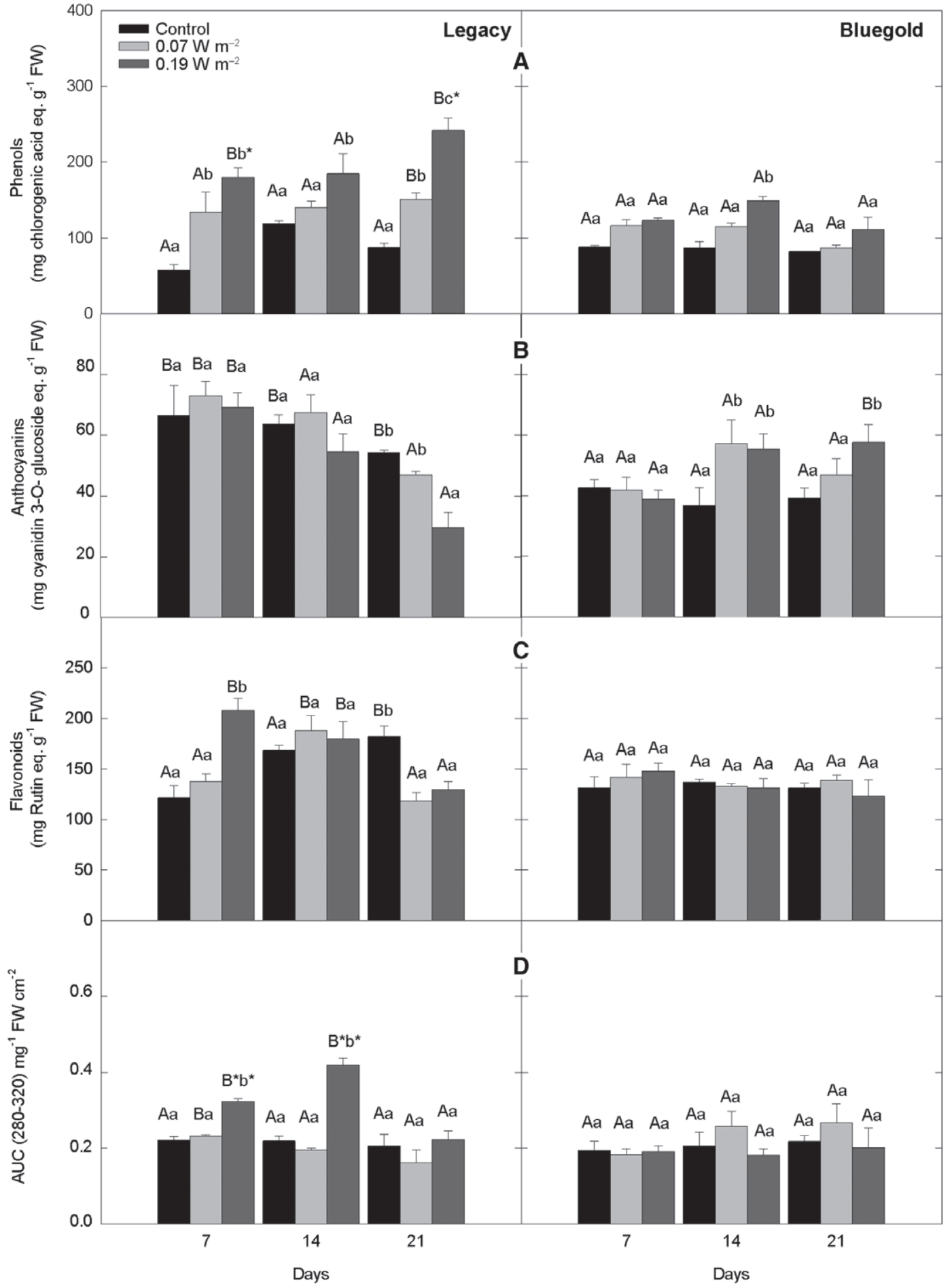

Fig. 4. Total phenols (A), anthocyanins (B), flavonoids (C) and UV-B absorbing capacity (D) from leaves of $V$. corymbosum cultivars grown under different UV-B light treatments at different time periods, measured as chlorogenic acid, cyanidin-3-glucoside, rutin equivalents and area under the curve (AUC) integrated between 280 and $320 \mathrm{~nm}$, respectively. All values correspond to the average of three replicates each $\pm \mathrm{SE}$. Different lower case letters indicate statistically significant differences among treatments for the same cultivar and exposure time. Different upper case letters indicate differences (Tukey's HSD at $P \leq 0.05$ ) between cultivars for the same exposure time and treatment. 
Table 3. Compounds induced by UV-B radiation in leaves of Vaccinium corymbosum plants growing under UV-B treatments for 21 days. Treatments: low, $0.07 \mathrm{~W} \mathrm{~m}^{-2} \mathrm{UV}-\mathrm{B}$; high, $0.19 \mathrm{~W} \mathrm{~m}^{-2} \mathrm{UV}-\mathrm{B}$. Details of compound characterization can be found in Table S4.

\begin{tabular}{|c|c|c|c|c|}
\hline \multirow[t]{2}{*}{ Cultivar } & \multirow[t]{2}{*}{ Class } & \multirow[t]{2}{*}{ ID } & \multicolumn{2}{|c|}{ UV-B treatment $\left(\mathrm{W} \mathrm{m}^{-2}\right)$} \\
\hline & & & 0.07 & 0.09 \\
\hline \multicolumn{5}{|l|}{ Legacy } \\
\hline & Phenolic acid & Dicaffeoylquinic acid & + & - \\
\hline & & Caffeoylshikimic acid & + & + \\
\hline & & 5-O-Feruoylquinic acid & + & + \\
\hline & Flavonol & Kaempferol glucoside (sodium adduct m/z 535) & & + \\
\hline & & $\begin{array}{l}\text { Kaempferol glucoside (sodium adduct m/z } 419 \\
\text { Kaempferol Arabinoside) }\end{array}$ & + & - \\
\hline & & Kaempferol 3-O-(6"-O-malonyl) glucoside & - & + \\
\hline & & Myricetin-3-xyloside & + & - \\
\hline & & Quercetin-3-rhamnoside & + & + \\
\hline & & Ishoramnetin-3-rutinoside & + & - \\
\hline & & Ishoramnetin-3-glucoside & + & - \\
\hline & & Kaempferol-7-O-rhamnoside & - & + \\
\hline & Flavonone & Pentahydroxyflavanone-A hexoside & + & + \\
\hline & Flavan 3 ol & Epicatechin & + & + \\
\hline & & Gallocatechin & + & + \\
\hline \multicolumn{5}{|l|}{ Bluegold } \\
\hline & Phenolic acid & 5-O-Feruoylquinic acid & + & - \\
\hline & & Myricetin-3-xyloside & + & - \\
\hline & Flavonol & Isorhamnetin & + & + \\
\hline & & Prodelphynidin B3 & + & - \\
\hline
\end{tabular}

in herbaceous species than in woody perennial plants (Giordano et al. 2004). Nonetheless, under a daily UV-B course simulation, we found that in $V$. corymbosum UV-B reduced stem growth ( $>60 \%$; Table 1$)$, with both cultivars being equally affected regardless of the UV-B dose. We also observed that $\mathrm{CO}_{2}$ assimilation in Legacy was not directly affected by UV-B exposure and therefore it cannot be associated with reduced plant growth; by contrast, in Bluegold a direct relationship was found between $\mathrm{CO}_{2}$ assimilation and growth. In addition, $\mathrm{CO}_{2}$ assimilation decayed at the end of the experiment in Bluegold. This decrease in $\mathrm{CO}_{2}$ assimilation rates has been associated with damage to the light harvesting complexes, disruption of thylakoid membrane integrity, inactivation of RuBisCO or a change in stomata conductance (Takeuchi et al. 2002, Kosobryukhov et al. 2015).

It is known that UV-B can increase ROS production in UV-B-sensitive plants, affecting the photosynthetic apparatus (Strid et al. 1994, Agrawal and Mishra 2009, Kataria et al. 2014). The plant low capacity to screen this radiation from the photosynthetic tissues is an indicator of UV-B sensitivity (Middleton and Teramura 1993). Consequently, the evaluation of this response on isolated chloroplasts gives information about the incoming intensity of UV-B reaching these organelles (Hideg et al. 2013). In our experiment, Bluegold increased $\mathrm{H}_{2} \mathrm{O}_{2}$ production in chloroplasts sooner than Legacy under low UV-B radiation (Fig. 2A). Thus, we believe that the intake of this radiation to the inner cell layers was stronger in the first days of treatment in Bluegold. In fact, higher levels of chloroplast ROS were correlated negatively with increased LP ( $r=-0.91)$ in Legacy (Fig. 5), whereas Bluegold exhibited a positive correlation with LP $(r=0.97)$ and total ROS at 21 days. The LP increase in Bluegold indicated higher sensitivity to UV-B during prolonged exposure (Fig. 2C). Furthermore, UV-B sensitivity in this cultivar may be associated with a decrease in $\mathrm{CO}_{2}$ assimilation (Table 2). Meanwhile, such physiological parameters were not affected in Legacy plants (Table 2).

Increases in the scavenging parameters under UV-B radiation treatments have been extensively discussed in different plant species (Hideg et al. 2013). The results obtained in the present study suggest that Bluegold counteracts the ROS accumulation with UV-B-enhancing SOD activity (Fig. 3B). Nonetheless, this response seemed to be insufficient to counteract the harmful effects of UV-B reflected in the increase in LP at the end of experiment.

Xanthophyll cycle compounds could be involved in the photosynthetic apparatus protection against UV-B radiation; however, this protection is poorly understood (Yang et al. 2007, Moon et al. 2011). In our study, we found a differential response to UV-B radiation in both cultivars with respect to xanthophyll pigments. Lt levels were increased in Bluegold with the highest UV-B dose, which is relevant because of the involvement of 

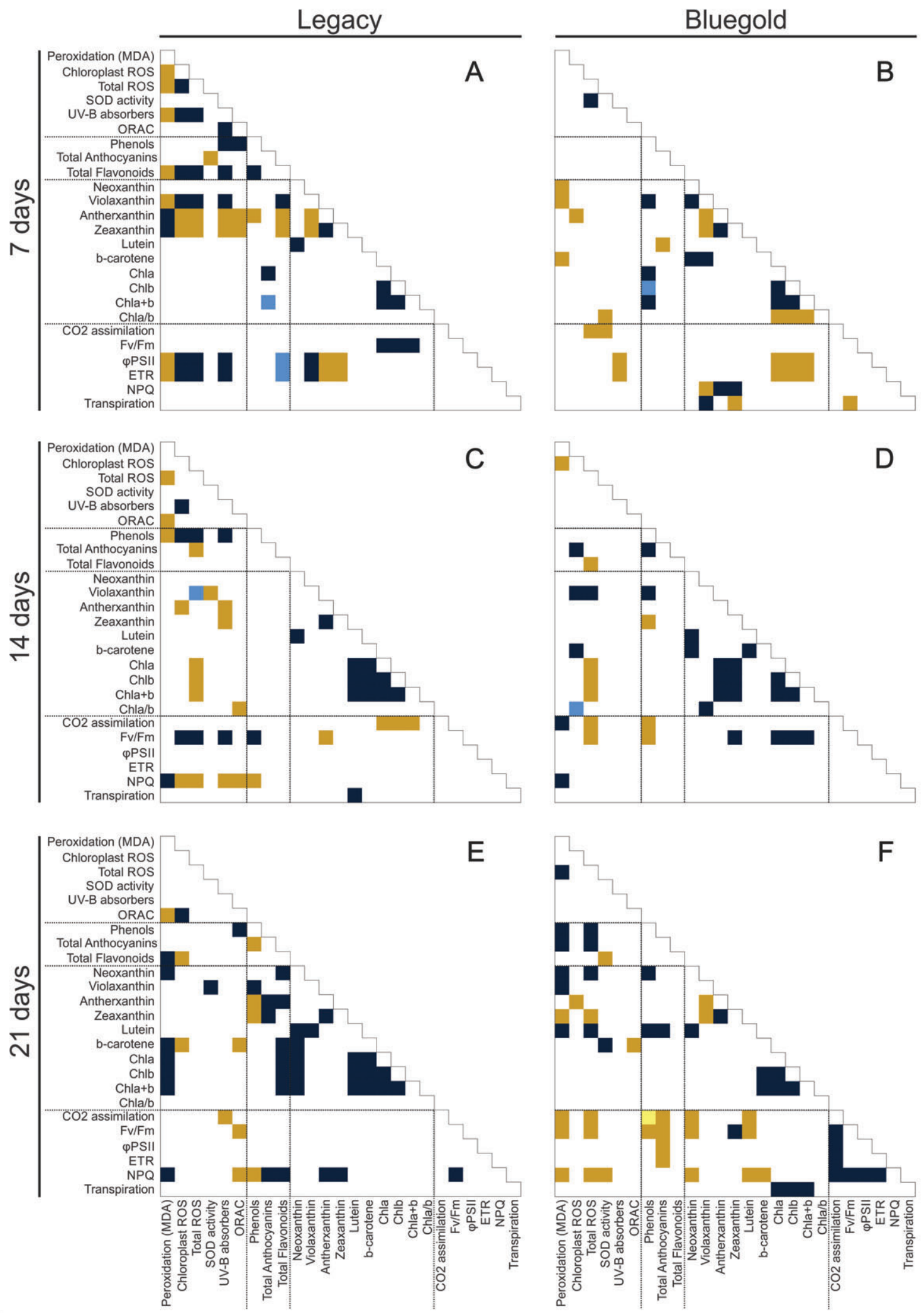

Fig. 5. Continued. 
this carotenoid in NPQ. This was demonstrated in the npq1 mutant of Arabidopsis, where the accumulation of $\mathrm{Lt}$ in the absence of Zx restored the NPQ ( $\mathrm{Li}$ et al. 2009). In this context, our results did not support this assumption because Bluegold decreased NPQ at the highest UV-B dose at the end of the experiment. Bluegold also increased $\beta \mathrm{Ca}$ at the end of the experiment. Yet despite this cultivar showing an increase in Lt and $\beta \mathrm{Ca}$, these compounds were not correlated with either NPQ or ORAC. Therefore, we suggest that in Bluegold plants these increases seem to be a UV-B stress response and not a UV-B resistance mechanism. The reduction of DEPS at the high UV-B radiation in Legacy and at both UV-B levels in Bluegold (Fig. 1) suggests that $V x$ de-epoxidase was inactivated by UV-B radiation, leading to an accumulation of $\mathrm{Vx}$ in both cultivars. In fact, the inhibition of $V x$ de-epoxidation by UV-B radiation has been reported previously in Pisum sativum (Pfündel et al. 1992), Cucumis sativus, Solanum lycopersicum and $A$. thaliana (Moon et al. 2011). However, these last authors reported that an increase in VDE/ZEP ratio in UV-B-treated plants indicated greater enzyme activity for de-epoxidation of $V x$ to $Z x$ than for $Z x$-epoxidase, which was not consistent with the NPQ suppression by UV-B (Moon et al. 2011). Although a central role of $\mathrm{pH}$ in thylakoid lumen acidification because of electron transport has been hypothesized to explain xanthophyll cycle activation and NPQ, our results indicate that ETR was not affected in either cultivar by UV-B radiation (Table 2). This confirms our assumption about the possible inhibition of $\mathrm{Vx}$ de-epoxidase by UV-B exposure.

Another important response to UV-B radiation is the increase in phenylpropanoid compounds (Caldwell et al. 1983, Li et al. 1993, Landry et al. 1995, Hectors et al. 2007, Jenkins 2009, Randriamanana et al. 2015). Both flavonoids and hydroxycinnamic derivatives are widely reported to be sunscreens (Rozema et al. 1997, Fischbach et al. 1999, Tilbrook et al. 2013). Our findings indicate that flavonoid accumulation is responsive to UV-B, increasing in concentration in Legacy at the highest UV-B dose at 7 days (Fig. 4C). However, we observed a null response in this cultivar with respect to anthocyanins (Fig. 4B). Anthocyanins have been previously reported as being induced by stress factors in $V$. corymbosum (Inostroza-Blancheteau et al. 2014, Rojas-Lillo et al. 2014, Yañez-Mansilla et al. 2015, Reyes-Díaz et al. 2016). In our case, these cultivars did not show a clear induction of anthocyanins under UV-B radiation. Bluegold did show an increase of these metabolites at 14 and 21 days, but this response seems to be associated with stress conditions and not particularly with a UV-B photoprotective mechanism, because this cultivar was damaged by UV-B treatments.

The accumulation of UV-B absorbing compounds (UAC), a common response strategy to UV-B in plants, was induced in our experiment. Legacy showed an increase in these compounds earlier (7 days), maintaining higher levels than the control at the highest UV-B treatment. A contradictory behavior was found in Bluegold, where UAC did not change during the exposure to UV-B radiation (Fig. 4D).

Flavonols can contribute as a UV-B radiation exclusion mechanism. Our findings suggest that Legacy has a higher pool and wider variety of UV-B photoprotective compounds than Bluegold, biosynthesizing mostly flavonol glycosides, which could afford some advantages in the avoidance of UV-B stress. All these molecules strongly absorb in the UV-B range $(280-320 \mathrm{~nm})$, which is consistent with other reports (Caldwell et al. 1983, Emiliani et al. 2013). The glycosylation of these molecules also reduces their antioxidant capacity, giving the molecule greater stability and solubility (Pietta 2000). In fact, it is reported that a large number of these compounds are accumulated in vacuoles of epidermis cells (Solovchenko and Merzlyak 2008), where it is suggested they act as photoprotective compounds under UV radiation (Merzlyak et al. 2008).

According to Hideg et al. (2013) and based on our results about increased levels of ROS, LP and reduction in $\mathrm{CO}_{2}$ assimilation, Bluegold could be considered as developing a distress (a strong stress event following an unfavorable change in environmental conditions leading to metabolic damage), indicating that this cultivar is sensitive to UV-B radiation. By contrast, Legacy seems to be a UV-B-resistant cultivar because of a better photosynthetic and antioxidant performance.

\section{Conclusions}

The results of this study showed that, under a simulated daily course of UV-B radiation, the cultivars behaved

Fig. 5. Correlation matrices based on Pearson's correlation coefficients between antioxidative metabolism responses, secondary metabolites, pigments and photosynthetic parameters of Legacy and Bluegold cultivars. Correlation was calculated at three points 7 (A and B), 14 (C and D) and 21 (E and F) days and three UV-B radiance $\left(0,0.07\right.$ and $\left.0.19 \mathrm{~W} \mathrm{~m}^{-2}\right)$. Pearson coefficient that are significant at $P<0.05$ are indicated by dark and light shading, which means strong (0.67 to 1.0$)$ and weak (0.34 to 0.66$)$ correlation, respectively. Positive and negative correlations are distinguished by blue and yellow colors, respectively. 
differently under UV-B stress: while Legacy was UV-B resistant, Bluegold was UV-B sensitive. It is worth noting that Legacy revealed a combined strategy to cope with the intake of UV-B radiation, which is primarily better oriented to photoprotection (avoidance) and then to tolerate the impact of this radiation. This strategy was shown to be dose-dependent, and it is triggered early under high UV-B radiation in this cultivar. Interestingly, the behavior of Legacy under a high UV-B dose showed an initial increase in its UV-B absorbing capacity during the first week of treatment, where flavonoids seemed to have the main role. From the second week, plants responded by reprogramming their metabolism, thereby increasing their antioxidant capacity and augmenting the biosynthesis of phenolic molecules. However, the capacity of Legacy to synthesize a wider variety of phenolics than Bluegold may also be involved in increasing its efficiency to tolerate high doses of UV-B. In general, the capacity of Legacy to respond early to UV-B by reprogramming its metabolism is the main difference with the sensitive cultivar Bluegold, which seems to react later, leading to metabolic damage.

\section{Author contributions}

A. L.-E., M. R.-D and M.A. designed and coordinated the experiments. A. L.-E., M. R.-D., M. A. and C. I.-B. formulated the manuscript and A. L.-E., M. R.-D, M. A., C. I.-B, and A. N.-N revised and corrected it. P. A. performed the UV-B irradiance measurements. A. L.-E and M. R.-D carried out the physiological, biochemical and metabolic analyzes. M. M. and A. N. N. performed the statistical analysis.

Acknowledgements - The authors wish to thank the Fondo Nacional de Desarrollo Científico y Tecnológico, Government of Chile (FONDECYT Project N 1120917 and 1110726). Also, AL-E was supported by a PhD grant from the Comisión Nacional de Investigación Científica y Tecnológica de Chile (CONICYT at $\mathrm{N}^{\circ}$ 24121533). We also thank Berries San Luis Farm, Lautaro, Chile, for kindly providing the blueberry plants and Dr. Helen Lowry for revising the language of the manuscript. In addition, we wish to thank to Karina Godoy, Biochemist, for the measurements of chloroplast ROS and confocal images, Andrea Diaz, Biochemist for her assistance in SOD measurements and Gabriela Valdebenito, Chemist for the HPLC-MS analysis.

\section{References}

Agati G, Stefano G, Biricolti S, Tattini M (2009) Mesophyll distribution of 'antioxidant' flavonoid glycosides in
Ligustrum vulgare leaves under contrasting sunlight irradiance. Ann Bot 104: 853-861

Agrawal SB, Mishra S (2009) Effects of supplemental ultraviolet-B and cadmium on growth, antioxidants and yield of Pisum sativum L. Ecotoxicol Environ Saf 72: 610-618

Agrawal SB, Singh S, Agrawal M (2009) Ultraviolet-B induced changes in gene expression and antioxidants in plants. In: Jean-Pierre J (ed) Advances in Botanical Research, Vol. 52. Academic Press, XXX, pp 47-86

Ballare CL, Caldwell MM, Flint SD, Robinson SA, Bornman JF (2011) Effects of solar ultraviolet radiation on terrestrial ecosystems. Patterns, mechanisms, and interactions with climate change. Photochem Photobiol Sci 10: 226-241

Baroli I, Niyogi KK (2000) Molecular genetics of xanthophyll-dependent photoprotection in green algae and plants. Philos Trans R Soc Lond B Biol Sci 355: 1385-1394

Bieza K, Lois R (2001) An Arabidopsis mutant tolerant to lethal ultraviolet-B levels shows constitutively elevated accumulation of flavonoids and other phenolics. Plant Physiol 126: 1105-1115

Bolink EM, van Schalkwijk I, Posthumus F, van Hasselt PR (2001) Growth under UV-B radiation increases tolerance to high-light stress in pea and bean plants. Plant Ecol 154: $147-156$

Caldwell MM, Robberecht R, Flint SD (1983) Internal filters: prospects for UV-acclimation in higher plants. Physiol Plant 58: 445-450

Casati P, Campi M, Morrow D, Fernandes J, Walbot V (2011) Transcriptomic, proteomic and metabolomic analysis of UV-B signaling in maize. BMC Genomics 12: 321

Choi B, Roh K (2003) UV-B radiation affects chlorophyll and activation of rubisco by rubisco activase in Canavalia ensiformis L. leaves. J Plant Biol 46: 117-121

Clarke LJ, Robinson SA (2008) Cell wall-bound ultraviolet-screening compounds explain the high ultraviolet tolerance of the Antarctic moss, Ceratodon purpureus. New Phytol 179: 776-783

Conner JK, Neumeier R (2002) The effects of ultraviolet-B radiation and intraspecific competition on growth, pollination success, and lifetime female fitness in Phacelia campanularia and P. purshii (Hydrophyllaceae). Am J Bot 89: 103-110

De los Rios P, Acevedo P (2010) Effects of natural ultraviolet radiation exposure in inland water ecosystems of Chilean Patagonia. In: Collignon LN, Normand CB (eds) Photobiology: Principles, Applications and Effects. Nova Science Publishers, Hauppauge, pp 195-207

De los Rios P, Hauenstein E, Acevedo P, Jaque X (2007) Littoral crustaceans in mountain lakes of Huerquehue National Park (38S, Araucania region, Chile).

Crustaceana 80: 401-410 
Du Z, Bramlage WJ (1992) Modified thiobarbituric acid assay for measuring lipid oxidation in sugar-rich plant tissue extracts. J Agric Food Chem 40: 1566-1570

Emiliani J, Grotewold E, Falcone Ferreyra ML, Casati P (2013) Flavonols protect Arabidopsis plants against UV-B deleterious effects. Mol Plant 6: 1376-1379

Fedina I, Hidema J, Velitchkova M, Georgieva K, Nedeva D (2010) UV-B induced stress responses in three rice cultivars. Biol Plant 54: 571-574

Fischbach RJ, Kossmann B, Panten H, Steinbrecher R, Heller W, Seidlitz HK, Sandermann H, Hertkorn N, Schnitzler JP (1999) Seasonal accumulation of ultraviolet-B screening pigments in needles of Norway spruce (Picea abies (L.) Karst.). Plant Cell Environ 22: 27-37

Gaberščik A, Vončina M, Trošt T, Germ M, Björn LO (2002) Growth and production of buckwheat (Fagopyrum esculentum) treated with reduced, ambient, and enhanced UV-B radiation. J Photochem Photobiol B 66: 30-36

García-Plazaola JI, Becerril JM (1999) A rapid high-performance liquid chromatography method to measure lipophilic antioxidants in stressed plants: simultaneous determination of carotenoids and tocopherols. Phytochem Anal 10: 307-313

Giordano CV, Galatro A, Puntarulo S, Ballaré CL (2004) The inhibitory effects of UV-B radiation $(280-315 \mathrm{~nm})$ on Gunnera magellanica growth correlate with increased DNA damage but not with oxidative damage to lipids. Plant Cell Environ 27: 1415-1423

Grabsztunowicz M, Jackowski G (2012) Isolation of intact and pure chloroplasts from leaves of Arabidopsis thaliana plants acclimated to low irradiance for studies on Rubisco regulation. Acta Soc Bot Pol 82: 91-95

Hancock J, Hanson EJ (1986) Highbush Blueberry Nutrition. USA Cooperative Extension Service, Michigan State University, East Lansing

He J, Huang LK, Whitecross MI (1994) Chloroplast ultrastructure changes in Pisum sativum associated with supplementary ultraviolet (UV-B) radiation. Plant Cell Environ 17: $771-775$

Hectors K, Prinsen E, De Coen W, Jansen MAK, Guisez Y (2007) Arabidopsis thaliana plants acclimated to low dose rates of UV B radiation show specific changes in morphology and gene expression in the absence of stress symptoms. New Phytol 175: 255-270

Heim KE, Tagliaferro AR, Bobilya DJ (2002) Flavonoid antioxidants: chemistry, metabolism and structure-activity relationships. J Nutr Biochem 13: 572-584

Hideg É, Barta C, Kálai T, Vass I, Hideg K, Asada K (2002) Detection of Singlet Oxygen and Superoxide with Fluorescent Sensors in Leaves Under Stress by Photoinhibition or UV Radiation. Plant Cell Physiol 43: 1154-1164
Hideg É, Jansen MAK, Strid $\AA$ (2013) UV-B exposure, ROS, and stress: inseparable companions or loosely linked associates? Trends Plant Sci 18: 107-115

Hoffmann WA, Poorter H (2002) Avoiding bias in calculations of relative growth rate. Ann Bot 90: 37-42

Hui R, Li X, Chen C, Zhao X, Jia R, Liu L, Wei Y (2013) Responses of photosynthetic properties and chloroplast ultrastructure of Bryum argenteum from a desert biological soil crust to elevated ultraviolet-B radiation. Physiol Plant 147: 489-501

Huovinen P, Gómez I, Lovengreen C (2006) A five-year study of solar ultraviolet radiation in Southern Chile $\left(39^{\circ} \mathrm{S}\right)$ : potential impact on physiology of coastal marine algae? Photochem Photobiol 82: 515-522

Inostroza-Blancheteau C, Reyes-Díaz M, Arellano A, Latsague M, Acevedo P, Loyola R, Arce-Johnson P, Alberdi M (2014) Effects of UV-B radiation on anatomical characteristics, phenolic compounds and gene expression of the phenylpropanoid pathway in highbush blueberry leaves. Plant Physiol Biochem 85: 85-95

Jahns P, Holzwarth AR (2012) The role of the xanthophyll cycle and of lutein in photoprotection of photosystem II. Biochim Biophys Acta 1817: 182-193

Jambunathan N (2010) Determination and detection of reactive oxygen species (ROS), lipid peroxidation, and electrolyte leakage in plants. In: Sunkar R (ed) Plant Stress Tolerance. Humana Press, XXX, pp 291-297

Jansen MAK, Gaba V, Greenberg BM (1998) Higher plants and UV-B radiation: balancing damage, repair and acclimation. Trends Plant Sci 3: 131-135

Jenkins GI (2009) Signal transduction in responses to UV-B radiation. Annu Rev Plant Biol 60: 407-431

Kakani VG, Reddy KR, Zhao D, Sailaja K (2003) Field crop responses to ultraviolet-B radiation: a review. Agric Forest Meteorol 120: 191-218

Kanungo M, Dubey A, Kataria S (2013) Solar UV-B and UV-A/B exclusion affects growth and antioxidant enzymes in cucumber and wheat. Indian J Plant Sci 2: $63-72$

Kataria S, Jajoo A, Guruprasad KN (2014) Impact of increasing ultraviolet-B (UV-B) radiation on photosynthetic processes. J Photochem Photobiol B 137: 55-66

Klem K, Holub P, Štroch M, Nezval J, Špunda V, Tříska J, Jansen MAK, Robson TM, Urban O (2015) Ultraviolet and photosynthetically active radiation can both induce photoprotective capacity allowing barley to overcome high radiation stress. Plant Physiol Biochem 93: 74-83

Kolb C, Käser M, Kopecký J, Zotz G, Riederer M, Pfündel E (2001) Effects of natural intensities of visible and ultraviolet radiation on epidermal ultraviolet screening and photosynthesis in grape leaves. Plant Physiol 127: $863-875$ 
Kosobryukhov AA, Lyubimov VY, Kreslavski VD (2015) Adaptive mechanisms of photosynthetic apparatus to UV radiation. In: Tripathi BN, Müller M (eds) Stress Responses in Plants. Springer International Publishing, London, pp 59-78

Krizek DT, Mirecki RM, Britz SJ (1997) Inhibitory effects of ambient levels of solar UV-A and UV-B radiation on growth of cucumber. Physiol Plant 100: 886-893

Kumari R, Singh S, Agrawal SB (2009) Combined effects of psoralens and ultraviolet-B on growth, pigmentation and biochemical parameters of Abelmoschus esculentus L. Ecotoxicol Environ Saf 72: 1129-1136

Kusano M, Tohge T, Fukushima A, Kobayashi M, Hayashi $\mathrm{N}$, Otsuki H, Kondou $\mathrm{Y}$, Goto $\mathrm{H}$, Kawashima $\mathrm{M}$, Matsuda F, Niida R, Matsui M, Saito K, Fernie AR (2011) Metabolomics reveals comprehensive reprogramming involving two independent metabolic responses of Arabidopsis to UV-B light. Plant J 67: 354-369

Landry LG, Chapple CCS, Last RL (1995) Arabidopsis mutants lacking phenolic sunscreens exhibit enhanced ultraviolet-B injury and oxidative damage. Plant Physiol 109: 1159-1166

Li JY, Oulee TM, Raba R, Amundson RG, Last RL (1993) Arabidopsis flavonoid mutants are hypersensitive to UV-B irradiation. Plant Cell 5: 171-179

Li Z, Ahn TK, Avenson TJ, Ballottari M, Cruz JA, Kramer DM, Bassi R, Fleming GR, Keasling JD, Niyogi KK (2009) Lutein accumulation in the absence of zeaxanthin restores non-photochemical quenching in the Arabidopsis thaliana npq1 mutant. Plant Cell 21: 1798-1812

Lidon F, Ramalho J (2011) Impact of UV-B irradiation on photosynthetic performance and chloroplast membrane components in Oryza sativa L. J Photochem Photobiol B Biol 104: 457-466

Lidon FJ, Reboredo FH, Leitão AE, Silva MMA, Duarte MP, Ramalho JC (2012) Impact of UV-B radiation on photosynthesis - an overview. Emir J Food Agric 24: 546-556

Lin LZ, Harnly JM (2007) A screening method for the identification of glycosylated flavonoids and other phenolic compounds using a standard analytical approach for all plant materials. J Agric Food Chem 55: 1084-1096

Maxwell K, Johnson G (2000) Chlorophyll fluorescence. A practical guide. J Exp Bot 51: 659-668

Maxwell DP, Wang Y, Mclntosh L (1999) The alternative oxidase lowers mitochondrial reactive oxygen production in plant cells. Proc Natl Acad Sci USA 96: $8271-8276$

Mazza CA, Boccalandro HE, Giordano CV, Battista D, Scopel AL (2000) Functional significance and induction by solar radiation of ultraviolet-absorbing sunscreens in field-grown soybean crops. Plant Physiol 122: 117-126
McKenzie RL, Aucamp PJ, Bais AF, Björn LO, Ilyas M (2007) Changes in biologically-active ultraviolet radiation reaching the Earth's surface. Photochem Photobiol Sci 6: 218-231

Merzlyak MN, Melø TB, Naqvi KR (2008) Effect of anthocyanins, carotenoids, and flavonols on chlorophyll fluorescence excitation spectra in apple fruit: signature analysis, assessment, modelling, and relevance to photoprotection. J Exp Bot 59: 349-359

Middleton EM, Teramura AH (1993) The role of flavonol glycosides and carotenoids in protecting soybean from ultraviolet-B damage. Plant Physiol 103: 741-752

Mohammed A, Tarpley L (2010) Differential response of Southern US rice (Oryza sativa L.) cultivars to ultraviolet-B radiation. J Agron Crop Sci 196: 286-295

Moon YR, Lee MH, Tovuu A, Lee CH, Chung BY, Park YI, Kim JH (2011) Acute exposure to UV-B sensitizes cucumber, tomato, and Arabidopsis plants to photooxidative stress by inhibiting thermal energy dissipation and antioxidant defense. J Radiat Res 52: 238-248

Ou B, Hampsch-Woodill M, Prior RL (2001) Development and validation of an improved oxygen radical absorbance capacity assay using fluorescein as the fluorescent probe. J Agric Food Chem 49: 4619-4626

Pfündel EE (2003) Action of UV and visible radiation on chlorophyll fluorescence from dark-adapted grape leaves (Vitis vinifera L.). Photosynth Res 75: 29-39

Pfündel EE, Pan RS, Dilley RA (1992) Inhibition of violaxanthin deepoxidation by ultraviolet-B radiation in isolated chloroplasts and intact leaves. Plant Physiol 98: $1372-1380$

Pietta PG (2000) Flavonoids as antioxidants. J Nat Prod 63: 1035-1042

Pollastri S, Tattini M (2011) Flavonols: old compounds for old roles. Ann Bot 108: 1225-1233

Rabinovitch PS (2001) Studies of cell function. In: Current Protocols in Cytometry. John Wiley \& Sons Inc., New York, NY, USA

Randriamanana TR, Lavola A, Julkunen-Tiitto R (2015) Interactive effects of supplemental UV-B and temperature in European aspen seedlings: implications for growth, leaf traits, phenolic defense and associated organisms. Plant Physiol Biochem 93: 84-93

Reyes-Díaz M, Alberdi M, Mora ML (2009) Short-term aluminum stress differentially affects the photochemical efficiency of photosystem II in highbush blueberry genotypes. J Am Soc Hortic Sci 134: 1-8

Reyes-Díaz M, Inostroza-Blancheteau C, Millaleo R, Cruces E, Wulff-Zottele C, Alberdi M, Mora ML (2010) Long-term aluminum exposure effects on physiological and biochemical features of highbush blueberry cultivars. J Am Soc Hortic Sci 135: 1-11

Reyes-Díaz M, Meriño-Gergichevich C, Alarcón E, Alberdi M, Horst WJ (2011) Calcium sulfate ameliorates the 
effect of aluminum toxicity differentially in genotypes of highbush blueberry (Vaccinium corymbosum L.). J Soil Sci Plant Nutr 11: 59-78

Reyes-Díaz M, Meriño-Gergichevich C, Inostroza-Blancheteau C, Latsague M, Acevedo P, Alberdi M (2016) Anatomical, physiological, and biochemical traits involved in the UV-B radiation response in highbush blueberry. Biol Plant 60: 355-366

Ribera AE, Reyes-Díaz M, Alberdi M, Zuñiga GE, Mora ML (2010) Antioxidant compounds in skin and pulp of fruits change among genotypes and maturity stages on highbush blueberry (Vaccinium corymbosum L.) grown in southern Chile. J Soil Sci Plant Nutr 10: 509-536

Rice-Evans CA, Miller NJ, Bolwell PG, Bramley PM, Pridham JB (1995) The relative antioxidant activities of plant-derived polyphenolic flavonoids. Free Radic Res 22: $375-383$

Rice-Evans CA, Miller NJ, Paganga G (1996) Structure-antioxidant activity relationships of flavonoids and phenolic acids. Free Radic Bio Med 20: 933-956

Rojas-Lillo Y, Alberdi M, Acevedo P, Inostroza-Blancheteau C, Rengel Z, Mora ML, Reyes-Díaz M (2014) Manganese toxicity and UV-B radiation differentially influence the physiology and biochemistry of highbush blueberry (Vaccinium corymbosum) cultivars. Funct Plant Biol 41: 156-167

Roy MK, Koide M, Rao TP, Okubo T, Ogasawara Y, Juneja LR (2010) ORAC and DPPH assay comparison to assess antioxidant capacity of tea infusions: relationship between total polyphenol and individual catechin content. Int J Food Sci Nutr 61: 109-124

Rozema J, van de Staaij J, Björn LO, Caldwell M (1997) UV-B as an environmental factor in plant life: stress and regulation. Trends Ecol Evol 12: 22-28

Ruhland C, Fogal M, Buyarski C, Krna M (2007) Solar ultraviolet-B radiation increases phenolic content and ferric reducing antioxidant power in Avena sativa. Molecules 12: 1220-1232

Sadzawka A, Carrasco MA, Demanet R, Flores H, Grez R, Mora ML, Neaman A (2004) Métodos de análisis de tejidos vegetales. Comisión de Normalización y Acreditación, Vol. 113. Sociedad Chilena de la Ciencia del Suelo, Santiago

Semerdjieva SI, Sheffield E, Phoenix GK, Gwynn-Jones D, Callaghan TV, Johnson GN (2003) Contrasting strategies for UV-B screening in sub-Arctic dwarf shrubs. Plant Cell Environ 26: 957-964

Slinkard K, Singleton VL (1977) Total phenol analysis: automation and comparison with manual methods. Am J Enol Vitic 28: 49-55

Solovchenko A, Merzlyak M (2008) Screening of visible and UV radiation as a photoprotective mechanism in plants. Russ J Plant Physl 55: 719-737
Strack D, Wray V (1989) Anthocyanins. In: Harborne JB (ed) Methods in Plant Biology. Plant Phenolics, Vol. 1. Academic Press/Harcourt Brace Jovanovich, London

Strid A, Chow W, Anderson J (1994) UV-B damage and protection at the molecular level in plants. Photosynth Res 39: 475-489

Takeuchi A, Yamaguchi T, Hidema J, Strid A, Kumagai T (2002) Changes in synthesis and degradation of Rubisco and LHCII with leaf age in rice (Oryza sativa L.) growing under supplementary UV-B radiation. Plant Cell Environ 25: $695-706$

Teramura A, Sullivan J (1994) Effects of UV-B radiation on photosynthesis and growth of terrestrial plants.

Photosynth Res 39: 463-473

Tilbrook K, Arongaus AB, Binkert M, Heijde M, Yin R, Ulm R (2013) The UVR8 UV-B photoreceptor: perception, signaling and response. Arabidopsis Book 11: e0164

Yañez-Mansilla E, Cartes P, Reyes-Díaz M, Ribera-Fonseca A, Rengel Z, Alberdi M (2015) Leaf nitrogen thresholds ensuring high antioxidant features of Vaccinium corymbosum cultivars. J Soil Sci Plant Nutr 15: 574-586

Yang SH, Wang LJ, Li SH, Duan W, Loescher W, Liang ZC (2007) The effects of UV-B radiation on photosynthesis in relation to photosystem II photochemistry, thermal dissipation and antioxidant defenses in winter wheat (Triticum aestivum L.) seedlings at different growth temperatures. Funct Plant Biol 34: 907-917

Zhishen J, Mengcheng T, Jianming W (1999) The determination of flavonoid contents in mulberry and their scavenging effects on superoxide radicals. Food Chem 64: 555-559

Zhu PJ, Yang L (2015) Ambient UV-B radiation inhibits the growth and physiology of Brassica napus L. on the Qinghai-Tibetan plateau. Field Crop Res 171: 79-85

Zoratti L, Karppinen K, Luengo-Escobar A, Häggman H, Jaakola L (2014) Light-controlled flavonoid biosynthesis in fruits. Front Plant Sci 5: 1-16

\section{Supporting Information}

Additional Supporting Information may be found in the online version of this article:

Fig. S1. Daily course of UV-B simulation $(280-320 \mathrm{~nm})$ in greenhouse experiment.

Fig. S2. Confocal laser microscopy images from leaves of Vaccinium corymbosum cultivars under UV-B treatment for 7 days.

Table S1. Chlorophyll concentration detected by HPLC-DAD of two highbush blueberry cultivars under control and UV-B radiation conditions. 
Table S2. Relative total leaf fluorescence intensity on Vaccinium corymbosum cultivars exposed to UV-B radiation for 7 days.

Table S3. Correlation matrices based on Pearson correlation coefficients, between oxidative metabolism parameters, pigments and photosynthetic parameters of Legacy and Bluegold blueberry varieties, in 7,14 and 21 days of three UV-B irradiances.

Table S4. Compounds induced by UV-B radiation and detected by HPLC MS/MS in V. corymbosum cultivars under UV-B radiation at the end of the time point experiment. 